\title{
On Comparison and Enlightenment of the Training System of Civil Servants in China and Australia
}

\author{
Zhan-tao $\mathrm{HE}^{1, \mathrm{a},{ }^{*}}$ \\ ${ }^{1}$ Tianjin University of Commerce, Tianjin 300134, China \\ ahezhantao_tj@sina.com
}

Keyword: Civil servant training, Australia, Comparison, Enlightenment.

\begin{abstract}
Civil servant training has become the demand and development trend of modern society, only by updating the concept and methods of civil service training constantly, can we adapt to the rapid development of China's economy and the diversification of social needs. The pertinence and validity of the Australian civil servant training system, embodies the commonness of Europe and other developed countries, basing on the comparison of the content about Chinese and Australian civil service training system, summarizes enlightenment of the reform of China's civil service training system, we should promote the training of legalization, standardization, enhance the training pertinence and practicality, advocate the training method being flexible and varied, improve the training effect and ability.
\end{abstract}

\section{Introduction}

At present, our country is in the key period of building an all-round well-off society and the crucial stage of deepening the reform and opening up, accelerate the transformation of economic development approach, therefore we put forward higher requirements to the comprehensive quality ability of civil servants. Only through different levels of training and knowledge update on civil servants, it is possible to meet all kinds of needs. Civil servant training is an important way to improve the quality and level of the civil servant, and it is also an objective requirement to adapt to the social and economic changes. At present, countries all over the world putting establishing the civil service training system, as an important part of the civil service system, and it has also reflected the needs of the times and the development trend of modern society. The pertinence and validity of the Australian civil servant training system, not only embodies the commonness of Europe and other developed countries, it also has its own remarkable characteristics, Therefore, comparing the Chinese and Australian civil service training system concept and methods, analyzing and summarizing its experience and enlightenment deeply, there is a certain reference and reference significance to the reform of Chinese civil service training system.

\section{A Survey of the Development of the Training System for the Civil Servants in China and Australia}

After the founding of new China, in order to meet the needs of the construction of socialist development, our party and government organs at all levels aimed at establishing a party school, cadres schools and other training institutions, they carried on the large-scale training to the cadre; After 1953,the cadre education and training work gradually transferred to the in-service cadre training; After the party's the third Plenary Session of the 11th CPC Central Committee, party and government departments at all levels in accordance with the cadre of the four principles which is 
being revolutionary, young, professional knowledgeable, carried out a multi-form, multi-level, multi-channel training work, providing valuable experience for the establishment of the civil service training system. The Provisional Regulations On State Civil Servants made special regulations on the civil service training in 1993, the Interim Provisions of The Civil Service Training further refined and improved the civil service training system in 1996, until the implementation of the Civil Service Law of People's Republic of China in 2006, it marked the formal establishment of the civil service system in China, it not only has made the principle of the provisions in the hiring, assessment, post and other sections in the content of the training, but also set up a civil service training section, so that the civil service training on the track of the legal system, for example, the tenth chapter states: according to the requirements of the civil service duties and to improve the quality of civil servants, the civil service should be classified training[1].

Australian civil service system was established in 1902 originally, the first ten years there was not a clear civil service law, just set up a civil service office, which is responsible for the appointment of civil servants, pay, assessment and other affairs. In 1919-1921, Australia made the first draft of the civil law, and submit the federal Senate consideration, after 1 year of intense discussion and revision, in 1922, Australia's first Civil Service Act (Public Service Act 1999) officially approved the entry into force, it stipulates that all staff in the federal, state (autonomous region) and local governments, as well as overseas institutions of the government, are government's civil servants. In 1990, the Commonwealth of Australia government set up a national training joint committee; it carries out overall coordinated management of various types of training throughout the country. Until the introduction of the Civil Service Law in 1999, it marks the final establishment of the civil service system in Australia, the civil service training system for further standardization and institutionalization.

\section{Analysis and Comparison of the Training System of Civil Servants in China and Australia}

In our country, civil servant training refers to the education and training activities of the state administrative organs according to the needs of the society and the requirements of the position, through various forms of planning, organized to improve the quality of the national civil service quality [1]. The aim is to improve the quality of civil servants continuously in order to meet the needs of the increasing development of administrative affairs. The essence is to develop and train the human resources of government organs by means of training.

The essence of Australian civil service training is the human resources development project of the civil service and the merit system protection committee, it bases on the model of civil human resources requirements, through a variety of ways to cultivate and develop the ability of civil servants, emphasizing the pertinence and effectiveness of training, pay attention to the civil servant's personal occupation career planning, and makes a reasonable correlation between the training effectiveness and performance evaluation, but also investigates and feeds back the training situation of each organization regularly [2]. 


\section{Comparison of Training Contents and Methods of Chinese and Austrian Civil Servants}

China's civil service training is generally in accordance with the principle of less but proficient and the requirements of scientific, targeted, sets up training courses as public required courses, specialized courses and other elective courses. The training includes political theory (the training focus), professional knowledge, leadership and management skills, so including Marx's philosophy, the basic theory of the socialist, the rule of the party's political theory and other professional knowledge. The training takes the way of teaching in the room mainly, through the knowledge taught by teacher as the leading, what about the training needs is setting up courses in the discipline system as the center, and the training effect is often assessed by the system test[3].

Australian civil service training is rich in content, various training institutions have different priorities according to their own characteristics and the main service object, the trainees can also be free to choose training courses, the course for general servants focuses on the practical and operational; For the newly recruited civil servants, the course content in addition to introduce the civil service system, the organization structure, value concept, but also design professional closely courses from the job responsibility requirements; Courses offered to middle managers, focusing more on common or universal issues in management. There are various forms for training, including not only professional training, skills training, but also theoretical training and comprehensive management of quality training, and most of the training course is graduate level; Training has a strong pertinence, focusing on practicability, the key are team spirit, solving problems, innovation and development capabilities, to enhance the ability to respond to changes basing on training fundamentally.

\section{Comparison of Training Kinds of Chinese and Austrian Civil Servants}

There are four kinds of civil servants training in our country. First is the former training is non-leadership civil servants through examination as the director under section and other equivalent positions and levels in the implementation of pre service training, also known as the pre-service training. Second is the service training, mainly on the promotion of leadership positions in the civil service in the post office before or after a year of training, including the clerk was promoted to deputy chief, chief promoted to leadership positions above the deputy director and so on. Third is the professional training, refers to the state administrative organs of the temporary organization of some civil servants carries out a special business training, such as the census, economic census personnel training and so on. The fourth is on-the-job training, is the national administrative authorities plan to organize regularly training of civil servants in order to adapt to the current job, among the civil servants who are professional and technical positions, the professional and technical training should be carried out in accordance with the requirements of professional and technical personnel to continue learning.

The type of the Australian civil service training is also divided into four categories. The first is the pre-training for candidates within the probation period, in order to provide relevant work target, the basic knowledge of working standards and procedures for primary civil servants, to help them with organizational structure and values of the civil service system as soon as possible. The second is a new entry training for civil servants, the aim is to make every new recruits have the opportunity to get the ability to engage in their work. The third is for serving civil servants occupation education and training, to further improve the professional technical ability, 
so that it can't only be truly competent at present as the work, but also to constantly improve their skills, improve their comprehensive ability. The fourth is the continuing education for the civil service, which belongs to the national higher education of the graduate level, it through the third education institutions (continuing education institutions) to make up for which the civil service training system, training project can't provide, so that the civil servants can master new knowledge and new skills.

\section{Comparison of Training Institutions of Civil Servants in China and Australia}

China Civil Service Law stipulates that the state establish a special training institutions for civil servants, the organs can also be entrusted to other training institutions to bear the civil service training tasks according to the needs. Training institutions are divided into training competent institutions and training and education institutions. Training authorities are the personnel department, the organization department. Training and education institutions are: the first is the national executive house, which set up in September 1994, the school policy is new, modern, high level, socialization, straight to the State Council, the main training is the senior civil servants; The second is the local administrative college, all levels of party; The third is the other training institutions, including the cadre management college and the training of the task of the college, research institutes and so on.

There are a lot of training institutions in Australia, the training and education institutions are open and compatible, they compete with each other, and they are regulated by the market. Civil servants who need to be trained according to their supervisor and the recommendations of the department training plan to the training market in accordance with their training needs choosing the relevant training institutions, signing an agreement to accept the training. Each training institutions in accordance with their own strength and credibility fairly competition in the training market.

\section{The Comparison of Training Management and Training Results between China and Australia}

At present, China's civil service training management is the responsibility of the government personnel department. Government personnel departments at all levels are in charge of the principle of grading, comprehensive management of the national civil service training.

The Civil Service Law of the sixty-second specified that the implementation of the civil service training is the registration management system. Should issue a certificate of training to the national civil servants who participate in the training and the examination, and qualify the examination. The training of civil servants required funds charged in the corresponding channels in accordance with relevant state regulations [4]. At the same time, the training and learning performance of civil servants, as one of the contents of the civil service assessment and job promotion, is an important condition for the promotion of civil servants.

An important tool for Australia ability of civil servants training is the human resource capacity 360 degree feedback system, the mainly structure is composed of three evaluation sub table form which are self-assessment questionnaire, feedback score table and feedback results table, each assessment sub table corresponding to one of the civil service human resources capacity model of a certain ability indicators, in order to determine their own strengths and development needs, By collecting the information of 360 degree feedback and the difference between evaluation index weight, will eventually result and the ability of human resources training civil servants 
model contrast, find their own strengths and weaknesses ability, to further develop them, and improve the training effect.

\section{Enlightenment on the Reform of Civil Servant Training System in China}

Although there is a great difference between China and Australia in the political system, values, the cadre management system, in the civil service training, can't be the same either, but the training of civil servants in Australia education beneficial ideas and methods has certain reference significance to improve the training of civil servant of our country, and it can greatly improve the comprehensive quality of civil servants.

\section{Improve Legislation, Promote the Legalization and Standardization of Training}

Accelerate the improvement of the legal system of civil service training, institutionalization and standardization is the necessary way. There are only general principle rules about the training of civil servants in our country, but on how to implement, how to operate without the details of the provisions, so there is an urgent need of specialized training for civil servants and regulations, to make things such as training objectives, contents, methods, training institutions, management standards, assessment and registration clear; At the same time, put the government's responsible for the training of civil servants and civil service training as two aspects of a same event up to the height of rights and obligations, and throughout the whole process of administrative work, make the training work going according to law, gradually walking at the track of being institutionalized, legalized and standardized.

\section{Enrich the Training Content, Enhance the Pertinence and Practicability of the Training}

We should recognize that the training of civil servants are different in the knowledge background, work skills, personal development plan and other aspects have, so they will have different training needs [5]. Therefore, we should analyze the training needs, enrich training content, and develop the menu style training, as far as possible to meet the diverse needs of different levels of civil servants, realize the goal of training combined with personal development plan. At the same time, the training content should not only improve the quality of professional but pay more attention to the comprehensive quality, the application of knowledge should be targeted and practical, with the problem as the direction, with the ability as the core, focus on solving problems, coordinating the organization and innovating development capabilities, to adapt to the rapid economic development and the need for profound social change.

\section{Optimize the Integration of Educational Resources, and Promote Flexible and Diverse Training Methods}

In our country, different types of civil service training should be located at different levels and location, to achieve the best training effect, we must continue to strengthen the degree of professional training. To this end, on the one hand breaking the pattern of China's closing civil service training, changing the single indoor theoretical training, encouraging participation in social training institutions and market resources, achieving open and compatible, competing fairly, advantages complementary; On the other hand, pay attention to the flexibility and diversity of the training methods, full use of social resources, change the traditional cramming teaching mode, combining theory with social practice, using case discussion, role playing and other training methods, and promoting the diversification of training methods. 
Pay Attention to Actual Effect Evaluation, Improve the Training Effect and Ability

Scientific and effective evaluation can accurately reflect the quality of the training and the areas that need to be improved. Our country should strengthen the inspection and use of training results, pay attention to the evaluation of the training process, and stimulate the passion and enthusiasm of the students to participate in the training; After the training, doing a result of the questionnaire survey and assessment of job year-end performance appraisal tracking, and feedback the actual results to the training institutions of education, training and education institutions adjust the teaching system and content accordingly, after a systematic, holistic feedback, testing and improvement of the cycle of development, improve the quality of training and training levels constantly.

\section{Reference}

[1] Bai-Lin ZHANG. People's Republic of China civil servant law. China human affairs publishing house, Beijing, 2012, pp.234-249. (In Chinese)

[2] Information on http://gjs.mof.gov.cn. (In Chinese)

[3] Zhong-He LI. Comparison of the civil service system.CPC Central Party School Publishing House, Beijing, 2003, pp.270-298. (In Chinese)

[4] Xiao-Bo YU. Analysis on the status quo of China's civil service training: Reflection on the international trend $[\mathrm{J}]$. Journal of Yunnan Administration College, 2012 (05):115-118.(In Chinese)

[5] Jia-Qi LI. Status quo and Countermeasures of professional and technical management of civil servants [J]. China's administrative management, 2013(08):72-75. (In Chinese) 